\title{
A facile synthesis of mixed soft-segmented poly(urethane-imide)- polyhedral oligomeric silsesquioxone hybrid nanocomposites and study of their structure-transport properties
}

\author{
Dhorali Gnanasekaran ${ }^{\mathrm{a}, \mathrm{b}}$ and Boreddy S Reddy ${ }^{\mathrm{a}, *}$
}

\begin{abstract}
The structure-transport properties of mixed soft-segmented poly(urethane-imide) (MSPUI) membranes and their microstructures were investigated. Polypropylene glycol, polycaprolactone diol and bis(3-aminopropyl)-terminated polydimethylsiloxane were used as the soft segments in the membrane synthesis via a three-step polymerization reaction. The chemical structures of the MSPUI membranes were characterized using attenuated total reflectance Fourier transform infrared spectroscopy. Morphology and surface properties of the membranes were studied using scanning electron and atomic force microscopy techniques. Surface energy measurements indicated the enrichment of the hydrophobic soft segment in the membranes. The amorphous nature of the polymers was analysed using wide-angle X-ray diffraction. The effect of morphology on the permeability and selectivity of the membranes is discussed. Finally, membrane structure-transport property relationships were correlated.
\end{abstract}

Keywords: structure-property; microstructure; nanocomposites; mixed soft segments; POSS

\section{INTRODUCTION}

Mixed soft-segmented polymers are in great demand due to the possibility of having better control over properties for commercial applications. The soft segments in these polymers play an important role in determining the physical properties. The ability to tune the physical properties of polymeric membranes strongly depends on both the chemical structure and polar nature of the soft segments. Tereshatov et al. ${ }^{1}$ studied the properties of polyurethanes (PUs) containing polypropylene glycol (PPG) and polyethylene glycol (PEG) mixed soft segments. They reported that a higher PEG content increases the permeability of PU membranes without affecting the mechanical properties. PUs can be designed in such a way to have improved thermal and mechanical properties by changing the relative compositions of the soft segments. ${ }^{2-6}$ The physical and chemical properties of PUs are directly related to the chemical composition of their backbones that are strongly dependent on the composition, type and molecular weight of the soft segments.

Generally, the character of the soft segments must be carefully adjusted to attain the required property profile for desired applications. To improve the physical properties, mixed or special types of polyols as soft segments were used in the preparation of PUs. ${ }^{7-10}$ Separation of $\mathrm{CO}_{2}$ is an emerging technology used to reduce the impact of fossil fuel combustion. Therefore, in the field of membrane technology, gas transport studies are undertaken with a clear idea to understand the transport behaviour of membranes. Recently, many researchers have explored the utility of organic-inorganic hybrid membranes, because of their extraordinary properties arising from the synergizing effect of both components, as promising systems for various applications. ${ }^{11-14}$

Membranes with inorganic fillers, like polyhedral oligomeric silsesquioxone (POSS), embedded in polymer matrices have a great potential to provide high performance for gas separation, and also the preparation of these types of membranes has been found to be relatively easy. ${ }^{15}$ Further, the incorporation of nanosized inorganic particles in the membranes is one of the most interesting topics of research into gas-separation processes. This may be due to the incorporation of fillers by blending with polymers. This leads to the agglomeration of particles and formation of non-selective voids at the interface between the particles and the polymer matrix. Therefore, modification of fillers and matrices has become an expanding field of research, since the introduction of a variety of functional groups can improve the dispersion of fillers and change the chemical affinities of penetration in the membranes. Nanosized inorganic particles like POSS are reinforced with silica cages. POSS derivatives featuring $\mathrm{Si}-\mathrm{O}$ linkages in the form of a cage present a silicon atom at each vertex, with substituents coordinating

\footnotetext{
* Correspondence to: Boreddy S Reddy, Industrial Chemistry Laboratory, Central Leather Research Institute (Council of Scientific and Industrial Research), Chennai- 600 020, India. E-mail: induchem2000@yahoo.com

a Industrial Chemistry Laboratory, Central Leather Research Institute (Council of Scientific and Industrial Research), Chennai- 600020 , India

b Institute of Applied Materials, Department of Chemical Engineering, University of Pretoria, Pretoria 0002, South Africa
} 
around the tetrahedral silicon vertices. POSS-embedded polymeric membranes show higher gas permeabilities but similar or even improved gas selectivities compared to the base polymeric membranes. ${ }^{16-21}$

For the reasons mentioned above, we have designed mixed softsegmented poly(urethane-imide) (MSPUI)-POSS membranes to determine the separation properties of gases. In the study reported in the present paper, four kinds of poly(urethane-imide)-POSS membranes with PPG or polycaprolactone diol (PCL) or bis(3aminopropyl)-terminated polydimethylsiloxane (APPDMS) were synthesized. The main objective of the work was to improve the permeability, selectivity and thermal stability of the newly synthesized mixed soft-segmented polymeric membranes. The mixed soft-segmented PU membranes MSPUI-1, MSPUI-2 and MSPUI-3 showed higher selectivity than PUI membranes because of the dense packing of polymer matrices as a result of hydrogen bonds between ether/ester and urethane linkages in the membranes.

\section{EXPERIMENTAL \\ Materials}

Heptacyclopentyl tricycloheptasiloxane triol (Cy-POSS) was synthesized in our laboratory, the experimental details having been given in our previous report. ${ }^{22}$ Hexamethylene diisocyanate (HMDI; Merck, 95\%) was used as received. Bis(hydroxyalkyl)terminated polydimethylsiloxane (PDMS; $\bar{M}_{\mathrm{n}}=5600 \mathrm{~g} \mathrm{~mol}^{-1}$; Aldrich, 99\%), 4,4'-(hexafluoroisopropylidene)diphthalic dianhydride (6FDA; Aldrich, 99\%), PPG $\left(\bar{M}_{\mathrm{n}}=4000 \mathrm{~g} \mathrm{~mol}^{-1}\right), \mathrm{PCL}$ $\left(\bar{M}_{\mathrm{n}}=1000 \mathrm{~g} \mathrm{~mol}^{-1}\right)$ and APPDMS $\left(\bar{M}_{\mathrm{n}}=2500 \mathrm{~g} \mathrm{~mol}^{-1}\right.$; Aldrich, $99 \%$ ) were purified under vacuum. Dibutyltin dilaurate (DBTDL; Aldrich, 95\%) and tetrahydrofuran (THF; Rankem) were distilled before use. All other chemicals used were of analytical grade and were used as received.

\section{Fourier transform infrared spectroscopy}

Attenuated total reflectance Fourier transform infrared (ATR-FTIR) spectroscopy was performed using an MB 3000 FTIR spectrometer (PIKE Technologies), equipped with an ATR Smart Avatar Miracle attachment (zinc selenide crystal). The measurements were conducted at $2 \mathrm{~cm}^{-1}$ nominal resolution and 20 scans were recorded per spectrum from 600 to $4000 \mathrm{~cm}^{-1}$. The data were collected and analysed using GRAMS AI 7.0 software from the manufacturer.

\section{Thermogravimetric analysis}

TGA of the samples was performed with a TGA Q50-TA (PerkinElmer) instrument at a heating rate of $10{ }^{\circ} \mathrm{C} \mathrm{min}^{-1}$ up to $800{ }^{\circ} \mathrm{C}$ under nitrogen atmosphere. The weight of the samples was ca $10 \mathrm{mg}$.

\section{Scanning electron microscopy}

SEM analysis was performed using a JEOL 400 microscope. Samples were prepared by cutting a $1 \mathrm{~mm}$ thick cross-section from a coated membrane using a diamond-wafering saw. This section was then cut into a small arc-shaped specimen of approximately $3 \mathrm{~mm}$ in length. The arc-shaped specimen was then placed on an aluminium SEM stub with carbon tape so that the coated surface of the membrane was pointing upwards. SEM images were obtained from the flat surface of the hybrid membranes.

\section{Atomic force microscopy}

AFM images were obtained using a Nanoscope III multimode atomic force microscope (Digital Instruments Inc.) in air, using the contact mode. A triangular $\mathrm{Si}_{3} \mathrm{~N}_{4} \mathrm{NP}$ probe (Veeco Instruments) with a nominal cantilever spring constant of $0.12 \mathrm{~N} \mathrm{~m}^{-1}$ and nominal frequency of $20 \mathrm{kHz}$ was used. The tip height was $200 \mu \mathrm{m}$, with a nominal radius of $20 \mathrm{~nm}$.

\section{Wide-angle X-ray diffraction (WAXD)}

WAXD patterns were obtained using an XRD-6000 X-ray diffractometer (Shimadzu, Japan) with a Cu target (40 kV, 15 $\mathrm{mA}$ ) at a scanning rate of $88^{\circ} \mathrm{min}^{-1}$.

\section{Surface energy measurements}

The surface energy of the synthesized MSPUI membranes was measured using polar and non-polar solvents. The contact angles were measured at ambient temperature with the sessile drop method ${ }^{23}$ using a camera mounted on a microscope to record the drop image. A Digidrop (GBX) model goniometer was used with Windrop software. Double-distilled water and $n$-heptadecane were used as solvents for these studies. An average of the results obtained from three experiments was recorded for contact angle measurements.

\section{Permeation measurements}

Pure gas permeation properties of the MSPUI membranes were determined utilizing a variable pressure/constant volume apparatus. The upstream pressure was varied from 1 to $4 \mathrm{~atm}$ (101 to $405 \mathrm{kPa}$ ), while the downstream pressure was maintained at atmospheric pressure. The gas flow rates were calculated with a soap-film bubble flow meter. The temperature was maintained at $32( \pm 1){ }^{\circ} \mathrm{C}$. The detailed experimental procedure has been described by Madhavan and Reddy. ${ }^{24}$

\section{Synthesis of prepolyimide (PPI)}

6FDA ( $2 \mathrm{mmol}$ ) and $5 \mathrm{~mL}$ of THF were placed in a double-neck flask equipped with a nitrogen inlet and spiral condenser and then stirred with a magnetic stirrer until a clear solution was obtained. Then, HMDI ( $1 \mathrm{mmol}$ ) in $3 \mathrm{~mL}$ of THF was added slowly while stirring for $6 \mathrm{~h}$ at $90^{\circ} \mathrm{C}$. All the reactions were performed under nitrogen atmosphere. The synthetic route is shown in Scheme $1(A)$.

\section{Synthesis of prepolyurethane (PPU)}

A predetermined quantity of $\mathrm{OH}: \mathrm{NCO}$ groups (1:2 mol ratio) was placed in a beaker and an appropriate amount of THF solvent and two drops of DBTDL catalyst were added. The mixture was stirred for $4 \mathrm{~h}$ at $30^{\circ} \mathrm{C}$ under nitrogen gas. Four PPUs with different formulations were prepared. The experimental details are given in Table 1 and the synthetic strategy is shown in Scheme 1 (I).

\section{Synthesis of MSPUI-POSS}

PPU containing a known quantity of terminal NCO groups and a measured quantity of PPI were placed in a $100 \mathrm{~mL}$ three-necked round-bottom flask equipped with a stirrer and spiral condenser with drying tube and were refluxed at $90^{\circ} \mathrm{C}$ for $6 \mathrm{~h}$ (until complete evolution of $\mathrm{CO}_{2}$ ). The detailed chemical compositions of PUI and MSPUls are given in Table 1. Then, the resulting viscous solution was transferred to a Teflon-coated Petri dish and was kept overnight at $30^{\circ} \mathrm{C}$. All the dried membranes were kept in a hot-air oven at $150{ }^{\circ} \mathrm{C}$ for $7 \mathrm{~h}$ to remove the traces of THF. The synthetic route adopted is shown in Scheme $1(A+I)$. 


\section{Synthesize of mixed soft poly(urethane-imide)-POSS membranes}<smiles></smiles>

$\mathrm{R}=$ Hexamethylene $\quad$ Anhỵdride terminated prepolyimide

A

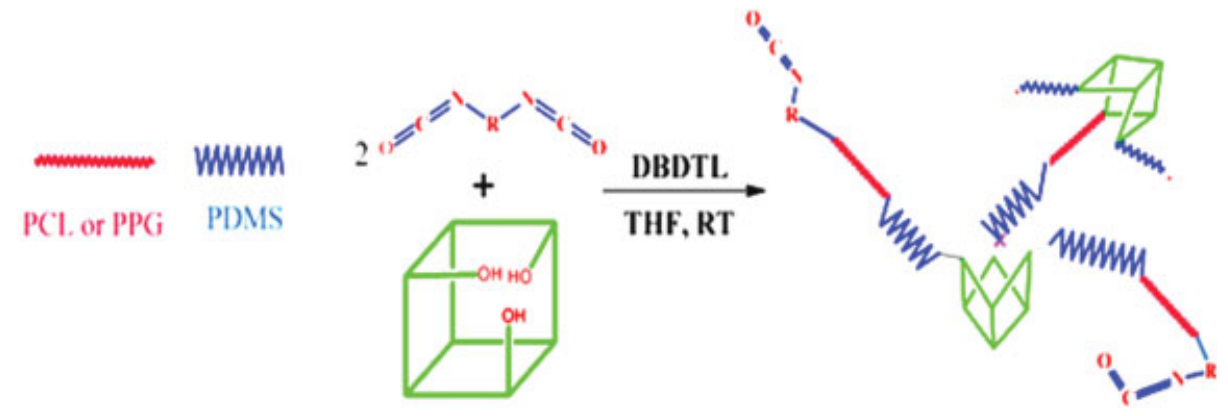

Isocyanate terminated prepolyurethane

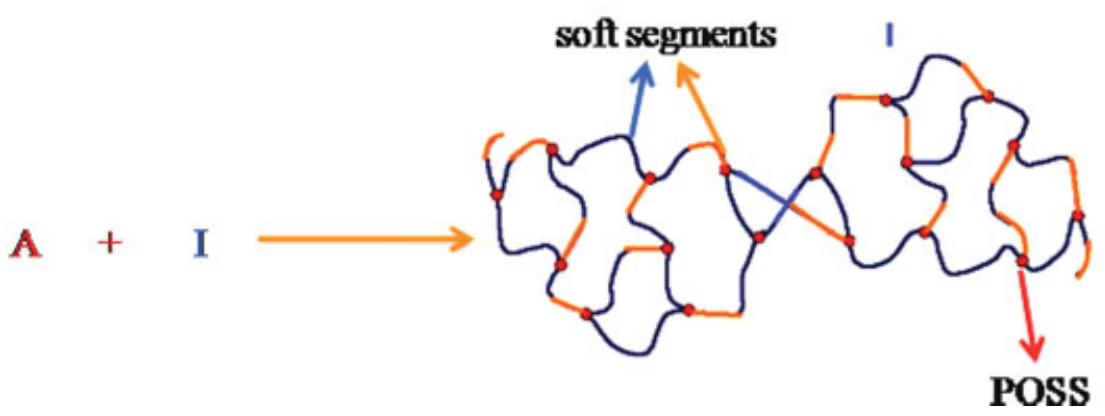

Scheme 1. Synthesis of mixed soft-segmented poly(urethane-imide)-polyhedral oligomeric silsesquioxone membranes.

Table 1. Chemical compositions of PUI, MSPUI-1, MSPUI-2 and MSPUI-3 membranes

\begin{tabular}{|c|c|c|c|c|c|c|c|c|}
\hline \multirow[b]{2}{*}{ Sample } & \multicolumn{5}{|c|}{ PPU (wt\%) } & \multicolumn{2}{|c|}{ PPI (wt\%) } & \multirow[b]{2}{*}{ Cy-POSS (wt\%) } \\
\hline & HMDI & PDMS & PPG & $\mathrm{PCL}$ & APPDMS & HMDI & $6 \mathrm{FDA}$ & \\
\hline PUI & 20 & 57.5 & - & - & - & 4.5 & 15.5 & 2.5 \\
\hline MSPUI-1 & 20 & 30 & - & - & 30 & 4.5 & 15.5 & 2.5 \\
\hline MSPUI-2 & 20 & 30 & - & 30 & - & 4.5 & 15.5 & 2.5 \\
\hline MSPUI-3 & 20 & 30 & 30 & - & - & 4.5 & 15.5 & 2.5 \\
\hline
\end{tabular}

\section{RESULTS AND DISCUSSION}

\section{ATR-FTIR spectroscopy}

Figure 1 shows the ATR-FTIR spectra of the MSPUI hybrid materials containing POSS and different soft segments (MSPUI-1, MSPUI-2 and MSPUI-3). The appearance of stretching vibrations at 3315 and $1726 \mathrm{~cm}^{-1}$ for $\mathrm{N}-\mathrm{H}$ groups and carbonyl groups, respectively, confirms the presence of urethane moieties.

All the hybrids are characterized by the characteristic bands at 1725 and $1777 \mathrm{~cm}^{-1}$, attributed to the symmetric and asymmetric stretching of imide $C=O$ groups. A shoulder peak at $1710 \mathrm{~cm}^{-1}$ is due to the hydrogen bonded urethane $\mathrm{C}=\mathrm{O}$. Figure 1 shows the characteristic $\mathrm{C}-\mathrm{N}$ stretching vibrations of imide at 1385 and
$1244 \mathrm{~cm}^{-1}$. Coleman et al. ${ }^{25}$ and Zharkov et al. ${ }^{26}$ reported that the carbonyl moiety of the urethane group associates with the ether group of the soft segment domains or at the interface shown by the absorption band at 1729 or $1733 \mathrm{~cm}^{-1}$. The broad band at $1116 \mathrm{~cm}^{-1}$ is due to the stretching vibration of $\mathrm{Si}-\mathrm{O}-\mathrm{Si}$ groups of PDMS/POSS and the band at $1027 \mathrm{~cm}^{-1}$ is due to the stretching vibration of $\mathrm{C}-\mathrm{O}-\mathrm{C}$ groups of PPG. The spectrum of the MSPUI-2 membrane shows a sharp absorption peak at $1690 \mathrm{~cm}^{-1}$ for (ester) $\mathrm{C}=\mathrm{O}$ bond. The disappearance of the characteristic peak for isocyanate groups around $2250-2275 \mathrm{~cm}^{-1}$ confirms the completion of the crosslinking reaction between the macromers and the isocyanate groups. 


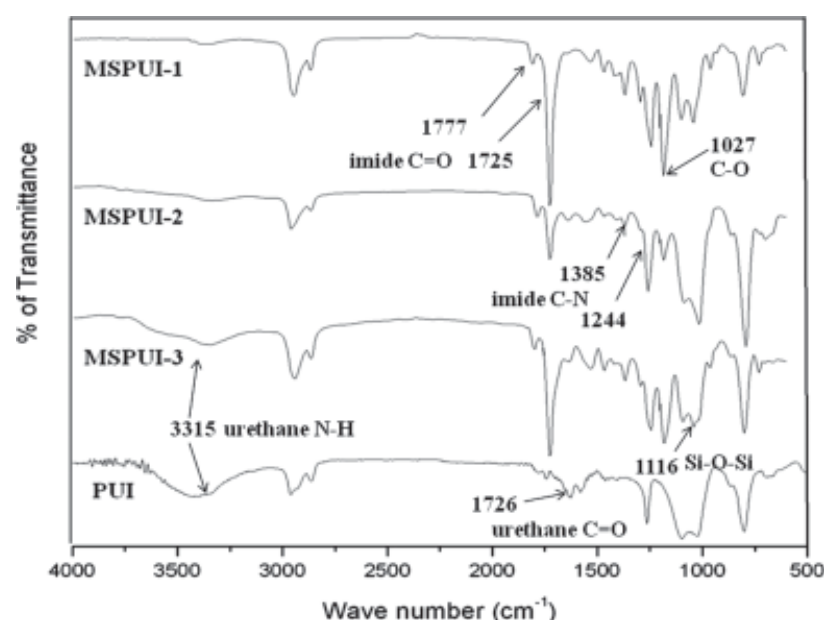

Figure 1. ATR-FTIR spectra of PUI, MSPUI-1, MSPUI-2 and MSPUI-3 membranes.

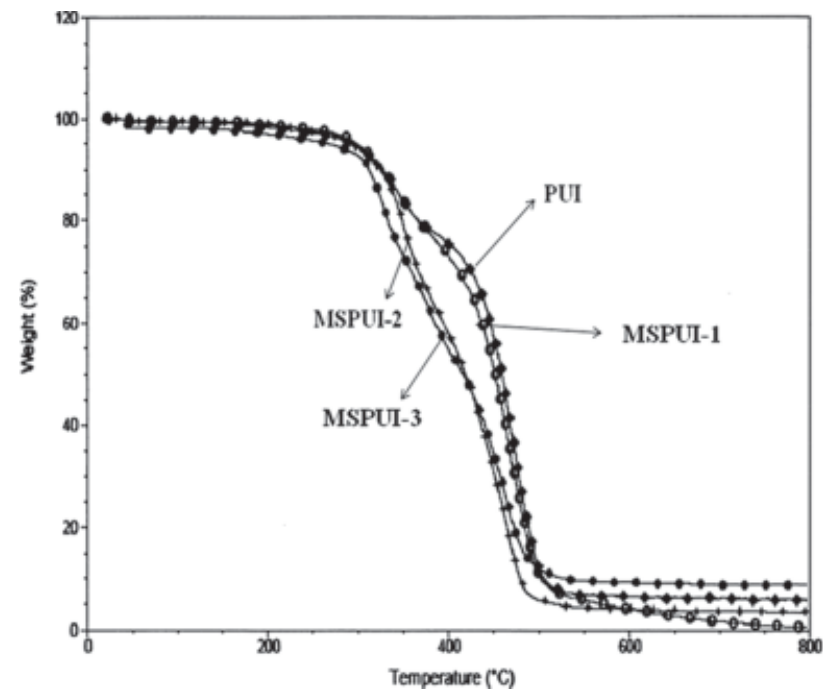

Figure 2. TGA curves of PUI, MSPUI-1, MSPUI-2 and MSPUI-3 membranes.

\section{TGA of PUI and MSPUls}

The thermal stability of PUI and MSPUI (MSPUI-1, MSPUI-2 and MSPUI-3) membranes were investigated using TGA. The plots are shown in Fig. 2. The TGA curve of PUI (single soft segment) is compared with those of MSPUIs (mixed soft segments). The mixed soft-segment-based PU containing APPDMS, namely MSPUI-1, is found to have improved thermal stability compared to MSPUI-2 containing PCL and MSPUI-3 containing PPG as soft segments. This may be due to the incorporation of thermally stable siloxane segments in the membranes. The thermal stability of MSPUI-2 is higher than that of MSPUI-3 due to the stronger interaction between the ester group of $\mathrm{PCL}$ and the $-\mathrm{NH}$ of the urethane group. The proper introduction of PPG or PCL or APPDMS into PUI matrices clearly indicates that their thermal stabilities mainly depend on the phase separation of PDMS with APPDMS or polyether (PPG) or polycaprolactone (PCL). It is also observed that the thermal stability is higher for PUI containing silioxane when compared to the other MSPUls reported here. The TGA results indicate that the thermal stability of the single-segmented and mixed soft-segmented PUIs are similar up to $350{ }^{\circ} \mathrm{C}$. The $50 \%$ thermal decomposition of the polymeric membranes is given in
Table 2. Thermal stability and surface energies of PUI, MSPUI-1, MSPUI-2 and MSPUI-3 membranes

\begin{tabular}{lcccc} 
Sample & $T_{50 \%}\left({ }^{\circ} \mathrm{C}\right)^{\mathrm{a}}$ & $\gamma_{\mathrm{s}}^{\mathrm{d}}\left(\mathrm{mN} \mathrm{m}^{-1}\right)$ & $\gamma_{\mathrm{s}}^{\mathrm{p}}\left(\mathrm{mN} \mathrm{m}^{-1}\right)$ & $\gamma_{\mathrm{sv}}\left(\mathrm{mN} \mathrm{m}^{-1}\right)$ \\
\hline PUI & 457 & 24.94 & 14.27 & 39.21 \\
MSPUI-1 & 450 & 26.07 & 11.02 & 37.09 \\
MSPUI-2 & 419 & 27.23 & 09.13 & 36.36 \\
MSPUI-3 & 403 & 28.03 & 07.68 & 35.71 \\
\hline
\end{tabular}

a $50 \%$ weight loss in TGA.

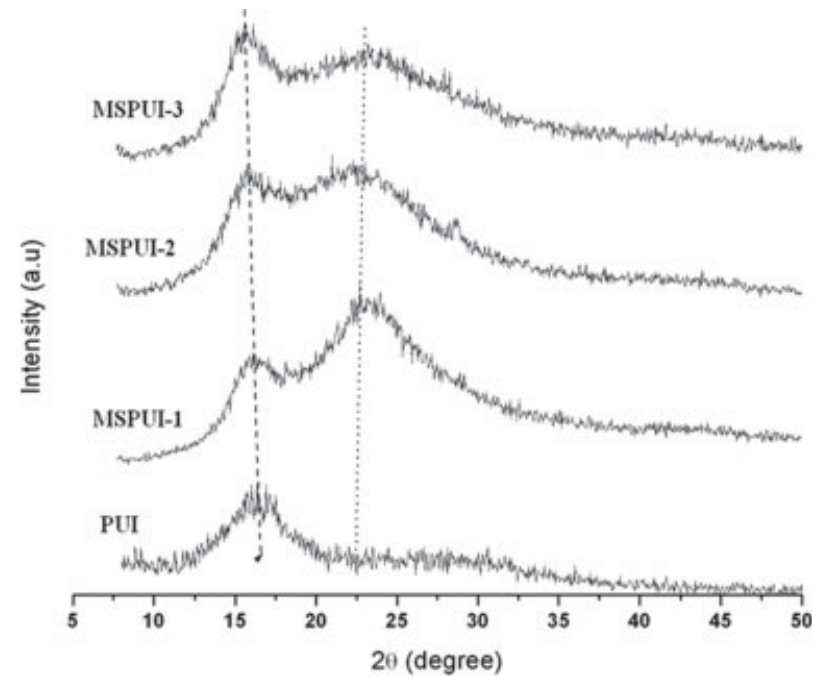

Figure 3. WAXD curves of PUI, MSPUI-1, MSPUI-2 and MSPUI-3 membranes.

Table 2. The weight loss occurs rapidly in the following order: MSPUI-3 > MSPUI-2 > MSPUI-1 > PUI.

\section{WAXD of PUI and MSPUls}

The WAXD patterns of PUI and MSPUI-1, MSPUI-2 and MSPUI-3 hybrid membranes containing POSS and mixed soft segments are shown in Fig. 3. Here, broad diffraction intensities are observed around $2 \theta=15-17^{\circ}$, which is due to the amorphous soft segments present in the matrices. A halo peak in the range $2 \theta=21.2-23.4^{\circ}$ reflects the amorphous $\mathrm{PU}$ groups present in the membrane matrix. After hybridization, the crystalline peaks of bulky POSS groups are absent in the patterns of the membrane matrices. This shows that the membranes are highly amorphous in nature.

Bragg's equation ${ }^{27}$ was used to calculate the interchain distance in the amorphous systems by measuring $\theta$ at maximum intensity in the scattering region. The WAXD peaks in amorphous polymer spectra are frequently used to estimate the average interchain spacing distance ( $d$-spacing). The first $d$-spacing values are found to be 5.6, 5.62, 5.76 and $5.92 \AA$ for PUI, MSPUI-1, MSPUI- 2 and MSPUI-3, respectively. The second $d$-spacing values observed for the hybrids are found to be 4.08, 4.04 and $3.97 \AA$ for MSPUI1, MSPUI-2 and MSPUI-3, respectively. A significant change in the interchain distance ( $d$-spacing) is observed as a result of introducing various soft segments, APPDMS, PCL and PPG, into the hybrid membranes.

\section{SEM analysis}

The microphase-separated morphologies of PUI, MSPUI-1, MSPUI-2 and MSPUI-3 hybrid membranes were studied using SEM analysis. 

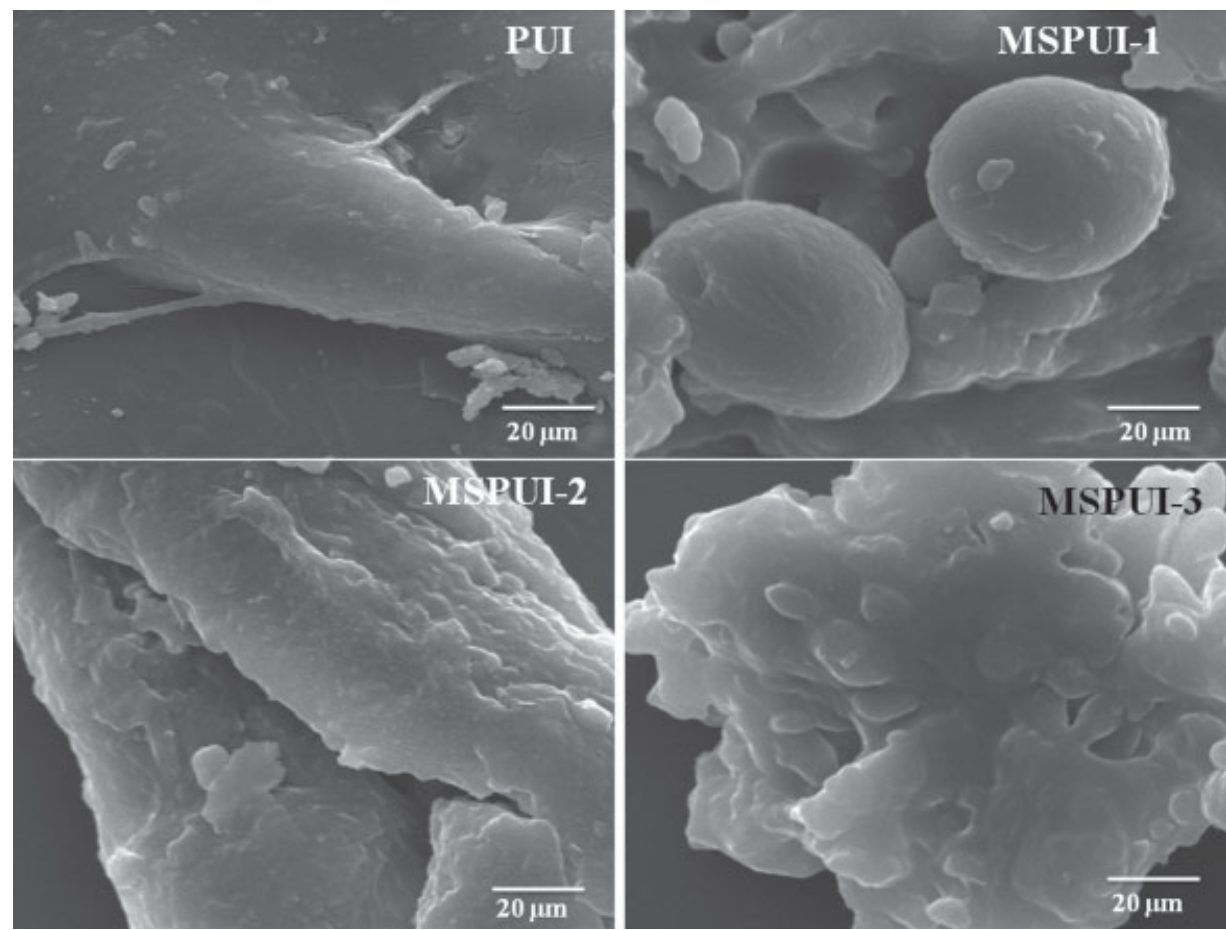

Figure 4. SEM images of PUI, MSPUI-1, MSPUI-2 and MSPUI-3 membranes.

SEM images are shown in Fig. 4. The hybrids MSPUI-2 and MSPUI-3 show interesting, more heterogeneous phase-separated morphologies and become dense and smooth by the aggregation of POSS nanomaterial. Aggregation is observed on the surface of the membranes due to the retardation of the mobility of the soft segments and POSS. The amount of phase separation for the synthesized MSPUI-3 based on PPG is more than that for MSPUI-2 based on PCL. This may be due to the different structures of PCL and PPG chains. The presence of methyl groups in the side chains of PPG prevents chain mobility and therefore increases the microphase separation compared to the PCL chains. The greater phase separation in the morphology of PPG-based PU, compared to the other PCL-, PDMS- and APPDMS-based MSPUIs, is observed in AFM analysis. Similar observations were reported by Srividhya and Reddy. ${ }^{28}$ This reveals that the highly hydrophobic nature and low surface energy of POSS molecules mainly contribute to the formation of POSS aggregates on the surface of the hybrid membranes. The phenomena of urethane/imide aggregation and microphase separation are possibly due to the incompatibility between the polar groups (urethane and imide groups) and the hydrophobic PDMS, APPDMS and POSS. However, it appears to be premature to conclude that the membranes are thoroughly free from defects, since a very small area of each membrane was viewed in SEM scanning.

\section{AFM analysis}

AFM has become an important tool for revealing the threedimensional nature of microphase-separated structures. The morphologies of the synthesized membranes were imaged using tapping-mode AFM which allows simultaneous detection of phase and surface roughness. The microphase-separated morphologies along with surface roughness for all hybrid membranes are shown in Fig. 5. The MSPUI-2 and MSPUI-3 hybrid membranes show a rough surface morphology with a heterogeneous phase separation because of the presence of PCL and PPG, respectively. This may not only be due to the incompatible nature of PPG and PCL soft segments with POSS but also due to chain collapsing of PDMS soft segment because of the presence of POSS in the membrane matrix. The incorporation of POSS in the organic polymers leads to microlevel aggregation of POSS nanoparticles due to the incompatibility of hydrophobic POSS molecules with the polymer matrices. ${ }^{29-31}$ In the phase images, the light regions correspond to the hardphase material (POSS) and the darker regions correspond to the soft-phase material (PDMS, PCL, PPG). From the AFM analysis of the membranes, visual evidence for the appearance of microphaseseparated structures is observed.

\section{Surface free energy of hybrid membranes}

The surface energy of the hybrid membranes was calculated and the results are listed in Table 2. PUI shows the highest surface energy of $39.21 \mathrm{mN} \mathrm{m}^{-1}$ because of the presence of single soft segment of siloxane. MSPUI-1, MSPUI-2 and MSPUI-3 show surface energies of $37.09,36.36$ and $35.71 \mathrm{mN} \mathrm{m}^{-1}$, respectively. This may be due to organic hydrocarbons such as PPG or PCL which are separated on the surface of the hybrid membranes. This confirms that the increase in the surface energy correspondingly decreases the phase separation of the mixed soft-segment membranes; the SEM results support this observation. Lin et al..$^{32}$ and Liu et al..$^{33}$ reported similar observations. As observed from the AFM images, the surfaces of MSPUI-1, MSPUI-2 and MSPUI-3 are distorted on changing the soft segments.

\section{Effect of different soft segments on permeability of PUI and MSPUI hybrid membranes}

The $\mathrm{N}_{2}, \mathrm{O}_{2}$ and $\mathrm{CO}_{2}$ gas permeability of PUI and MSPUI-1, MSPUI-2 and MSPUI-3 hybrid membranes is given in Table 3. The permeability behaviour of the MSPUIs is dependent on the type of soft segments present in the polymer matrix. The 


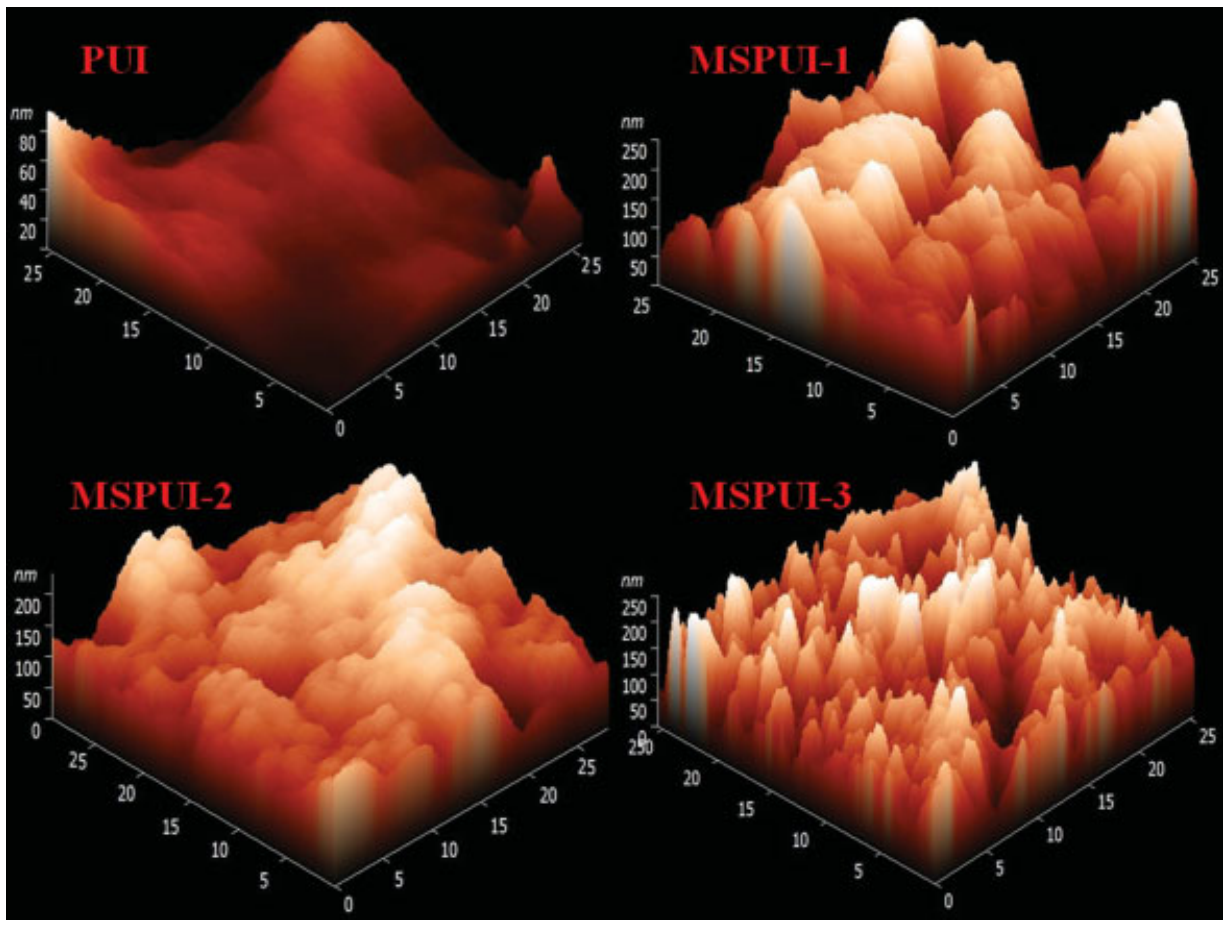

Figure 5. AFM images of PUI, MSPUI-1, MSPUI-2 and MSPUI-3 membranes.

Table 3. Permeability of PUI, MSPUI-1, MSPUI- 2 and MSPUI-3 hybrid membranes at various pressures

\begin{tabular}{|c|c|c|c|c|c|c|c|c|c|c|c|c|}
\hline \multirow[b]{2}{*}{ Sample } & \multicolumn{3}{|c|}{$1 \mathrm{~atm}$} & \multicolumn{3}{|c|}{$2 \mathrm{~atm}$} & \multicolumn{3}{|c|}{$3 \mathrm{~atm}$} & \multicolumn{3}{|c|}{$4 \mathrm{~atm}$} \\
\hline & $\mathrm{O}_{2}$ & $\mathrm{~N}_{2}$ & $\mathrm{CO}_{2}$ & $\mathrm{O}_{2}$ & $\mathrm{~N}_{2}$ & $\mathrm{CO}_{2}$ & $\mathrm{O}_{2}$ & $\mathrm{~N}_{2}$ & $\mathrm{CO}_{2}$ & $\mathrm{O}_{2}$ & $\mathrm{~N}_{2}$ & $\mathrm{CO}_{2}$ \\
\hline PUI & 420 & 230 & 1992 & 438 & 257 & 2045 & 470 & 277 & 2303 & 498 & 296 & 2545 \\
\hline MSPUI-1 & 395 & 201 & 1908 & 410 & 220 & 1994 & 451 & 250 & 2101 & 472 & 274 & 2378 \\
\hline MSPUI-2 & 370 & 170 & 1798 & 380 & 195 & 1891 & 427 & 221 & 1973 & 454 & 248 & 2233 \\
\hline MSPUI-3 & 345 & 150 & 1666 & 355 & 168 & 1753 & 398 & 180 & 1881 & 425 & 206 & 2013 \\
\hline
\end{tabular}

PPG-based membrane (MSPUI-3) has a lower permeability than the other polymeric membranes. Similar permeability changes were reported by Wolinska-Grabczyk and Jankowski. ${ }^{34}$ The PUI membrane shows a higher permeability coefficient than MSPUI-1, MSPUI-2 and MSPUI-3. Based on this observation, it is predicted that the penetrant molecules diffuse more favourably through the PDMS and APPDMS soft-segmented membranes. The higher permeability of PUI may be due to the presence of POSS and PDMS in the polymer matrix. This leads to an increase in the chain gap for better penetration of gas molecules, thereby acting as molecular spacers and chain stiffeners in the polymer. The SEM and AFM images confirm the protrusion of one phase and the surface roughness in the mixed soft-segmented membranes. This could be attributed to the existence of non-compatible phases. The permeability of $\mathrm{CO}_{2}$ gas is quite different, and increases with increasing pressure as evident from Table 3 . This may be due to the more condensable nature of $\mathrm{CO}_{2}$ gas molecules.

\section{Selectivity of PUI, MSPUI-1, MSPUI-2 and MSPUI-3 hybrid membranes}

The $\mathrm{O}_{2} / \mathrm{N}_{2}$ and $\mathrm{CO}_{2} / \mathrm{N}_{2}$ gas-pair selectivities of membranes containing various types of soft segments under 1-4atm (101-105 $\mathrm{kPa}$ ) pressure are given in Table 4. The gas-pair selectivities of PUI, MSPUI-1, MSPUI-2 and MSPUI-3 membranes are found to increase from 1.82 to 2.30 for $\mathrm{O}_{2} / \mathrm{N}_{2}$ and from 8.66 to 11.10 for $\mathrm{CO}_{2} / \mathrm{N}_{2}$

Table 4. Selectivity of PUI, MSPUI-1, MSPUI-2 and MSPUI-3 hybrid membranes at various pressures

\begin{tabular}{|c|c|c|c|c|c|c|c|c|}
\hline \multirow[b]{2}{*}{ Sample } & \multicolumn{2}{|c|}{$1 \mathrm{~atm}$} & \multicolumn{2}{|c|}{$2 \mathrm{~atm}$} & \multicolumn{2}{|c|}{$3 \mathrm{~atm}$} & \multicolumn{2}{|c|}{$4 \mathrm{~atm}$} \\
\hline & $\mathrm{O}_{2} / \mathrm{N}_{2}$ & $\mathrm{CO}_{2} / \mathrm{N}_{2}$ & $\mathrm{O}_{2} / \mathrm{N}_{2}$ & $\mathrm{CO}_{2} / \mathrm{N}_{2}$ & $\mathrm{O}_{2} / \mathrm{N}_{2}$ & $\mathrm{CO}_{2} / \mathrm{N}_{2}$ & $\mathrm{O}_{2} / \mathrm{N}_{2}$ & $\mathrm{CO}_{2} / \mathrm{N}_{2}$ \\
\hline PUI & 1.82 & 8.66 & 1.70 & 7.95 & 1.69 & 8.31 & 1.68 & 8.50 \\
\hline MSPUI-1 & 1.96 & 9.49 & 1.86 & 9.06 & 1.80 & 8.40 & 1.72 & 8.67 \\
\hline MSPUI-2 & 2.17 & 10.57 & 1.94 & 9.69 & 1.93 & 8.90 & 1.83 & 9.00 \\
\hline MSPUI-3 & 2.30 & 11.10 & 2.11 & 10.43 & 2.21 & 10.45 & 2.06 & 9.77 \\
\hline
\end{tabular}


at 1 atm. The $\mathrm{O}_{2} / \mathrm{N}_{2}$ gas-pair selectivity of the PUI membrane is lower than that of the other MSPUI-1, MSPUI-2 and MSPUI-3 hybrid membranes. The PDMS in the PUI membrane leads to less control of sieving small gases such as $\mathrm{N}_{2}$ and $\mathrm{O}_{2}$. The mixed soft-segmented MSPUI-1, MSPUI-2 and MSPUI-3 membranes show higher selectivity than the PUI membrane which indicates closer packing of polymer chain matrices as a result of hydrogen bonds between ether linkages of PPG or ester linkages of PCL and urethane linkages in the membranes.

\section{CONCLUSIONS}

A facile synthesis of mixed soft-segmented PUI-POSS membranes bearing different soft segments, i.e. APPDMS, PCL and PPG, was carried out. The influence of the mixed soft segments and POSS on the thermal and morphological properties was investigated using TGA, SEM, AFM and WAXD. The microscopic analysis of the MSPUIs confirmed the occurrence of phase separation of PCL in MSPUI-2 and of PPG in MSPUI-3. The surface energy estimation clearly showed the presence of hydrophobic groups on the surface of all the systems. The gas permeability and selectivity were altered by the presence of the various soft segments in the MSPUI polymeric membranes. Based on these results, the gas transport through a polymeric membrane with mixed soft segments was considerably dependent on its change of morphology as well as on its complex molecular arrangement. This suggested that the synthesized polymeric membranes displayed considerable improvement in thermal and transport properties compared with the PU control.

\section{ACKNOWLEDGEMENTS}

One of the authors (DG) thanks the Department of Science and Technology, New Delhi (no. SR/S1/PC-45/2011) for a Junior Research Fellowship and CSIR for a Senior Research Fellowship.

\section{APPENDIX: LIST OF ABBREVIATIONS}

6FDA 4,4'-(hexafluoroisopropylidene)diphthalic dianhydride AFM atomic force microscopy

APPDMS bis(3-aminopropyl)-terminated polydimethylsiloxane

ATR-FTIR attenuated total reflectance Fourier transform infrared spectroscopy

DBTDL dibutyltin dilaurate

HMDI hexamethylene diisocyanate

MSPUI mixed soft-segmented poly(urethane-imide)

PCL polycaprolactone diol

POSS polyhedral oligomeric silsesquioxone

PPG polypropylene glycol

SEM scanning electron microscopy

TGA thermogravimetric analysis

WAXD wide-angle X-ray diffraction

\section{REFERENCES}

1 Tereshatov VV, Senichev VY, Tereshatova EN and Makarova MA, in Handbook of Plasticizers, ed. by Wypych G. ChemTec, New York, p. 346 (2004).

$2 \mathrm{Hu} J \mathrm{~L}$ and Mondal S, Polym Int 54:764-774 (2005).

3 Park HB and Lee YM, J Membr Sci 197:283-296 (2002).

4 Jeong HM, Ahn BK and Kim BK, Polym Int 49:1714-1721 (2000).

5 Yilgor I and Yilgor E, Polymer 40:5575-5581 (1999).

6 Yen MS and Cheng KL, J Appl Polym Sci 52:1707-1717 (1994).

7 Chen CT, Zatoz RF, Chang PJ and Tobosky AV, J Appl Polym Sci 16:2105-2114 (1972).

8 Cooper SL, Phillips RA, Stevenson JC and Nagarajan MR, J Macromol Sci Phys B 27:245-274 (1988).

9 Cooper SL, Yu XH, Nagarajan MR, Grasel TG, Grasel PE and Gibson PE, J Polym Sci Polym Phys Ed 23:2319-2338 (1985).

10 Ahn TO, Jung S, Jeong HM and Lee SW, J Appl Polym Sci 51:43-49 (1994).

11 Madhavan K and Reddy BSR, J Membr Sci 342:291 - 299 (2009).

12 Bernardo P, Drioli E and Golemme G, Ind Eng Chem Res 48:4638-4668 (2009).

13 Joly C, Samaihi M, Porcar L and Noble RD, Chem Mater 11:2331-2338 (1999).

14 Gnanasekaran D and Reddy BSR, Clean Technol Environ Policy 15:383-389 (2013).

15 Shen Y and Lua AC, Chem Eng J 192:201-210 (2012).

16 Patel NP, Miller AC and Spontak RJ, Adv Mater 15:729-733 (2003).

17 Cornelius C, Hibshman C and Marand E, Sep Purif Technol 25:181-193 (2001).

18 Patel NP, Miller AC and Spontak RJ, Adv Funct Mater 14:699-707 (2004).

19 Ryu HS, Kim DG and Lee JC, Polymer 51:2296-2304 (2010).

20 Qiu J, Zheng JM and Pienemann KV, Macromolecules 39:4093-4100 (2006).

21 Reddy BSR and Gnanasekaran D, in Advances in Nanocomposites: Synthesis, Characterization and Industrial Applications, ed. by Reddy BSR. InTech, Rijeka, Croatia, pp. 195-226 (2011).

22 Gnanasekaran D, Madhavan K, Tsibouklis J and Reddy BSR, Austr J Chem 64:309-315 (2011).

23 Kuitian T and Obendorf SK, J Membr Sci 274:150-158 (2006).

24 Madhavan K and Reddy BSR, J Membr Sci 283:357-365 (2006).

25 Coleman MM, Lee KH, Skrovanek DJ and Painter PC, Macromolecules 19:2149-2157 (1986).

26 Zharkov VV, Strikovsky AG and Verteletskara TE, Polymer 34:938-941 (1993).

27 Srividhya M and Reddy BSR, J Polym Sci A: Polym Chem 45:1707-1726 (2007).

28 Srividhya M and Reddy BSR, J Membr Sci 296:65-76 (2007).

29 Liu LA, Tian MA, Zhang WA, Zhang LA and Mark JE, Polymer 48:3201-3212 (2007).

30 Lee YJ, Kuo SW, Huang WJ, Lee HY and Chang FC, J Polym Sci B: Polym Phys 42:1127-1136 (2004).

31 Misra R, Fu BX and Morgan SE, J Polym Sci B: Polym Phys 45:2441 - 2455 (2007).

32 Lin HC, Kuo SW, Huang CF and Chang FC, Macromol Rapid Commun 27:537-541 (2006).

33 Liu Y, Ni Y and Zheng S, Macromol Chem Phys 207:1842-1851 (2006).

34 Wolinska-Grabczyk A and Jankowski A, Sep Purif Technol. 57:413-417 (2007). 